\title{
Assessment of Subsurface Conditions in a Coastal Area of Lagos using Geophysical Methods
}

\author{
K. F. Oyedele*, S. Oladele, C. Okoh \\ Department of Geosciences, University of Lagos, Nigeria.
}

\begin{abstract}
An integrated geophysical and geotechnical survey was carried out at Magodo Estate, Lagos, Nigeria. The buildings in this area are either sinking or intensively affected by severe cracks showing structural instability. The survey was aimed at characterizing the shallow subsurface in order to delineate features that may have caused structural instability that led to cracking and sinking of the residential buildings in the area. To image the subsurface, resistivity profiling (2-D) using a Wenner array and Cone Penetration Test (CPT) was carried out on five profiles of length $180 \mathrm{~m}$ each. The acquired data were processed and interpreted integrally to image the shallow geotechnical setting of the site. Integrated interpretation led to the delineation of low resistivity, low bearing capacity clay which is identified as the main cause of instability that resulted in potentially dangerous cracking and sinking of residential buildings in the area.
\end{abstract}

KEYWORDS: Geo-materials, resistivity, geotechnical, geophysical.

[Received July 16 2015; Revised December 172015 \& December 23 2015; Accepted December 27 2015]

\section{INTRODUCTION}

The spate of building failures throughout the country has assumed an alarming dimension, with Lagos not been an exception. Lagos has been witnessing increase in real estate development due to increase in demand for shelters and office complexes necessitated by population explosion. As more areas are being developed, the need for pre - foundation studies has therefore become imperative so as to prevent loss of valuable lives and properties that always accompany such failures. Foundation studies usually provide subsurface information that aid in the design of structures. The combination of geophysical data and geotechnical measurements may greatly improve the quality of building construction in civil engineering (Soupios, et al, 2007). Engineering geophysics combined with geotechnical engineering focus on the behaviour and performance of soils and rocks in the design and construction of civil, environmental and mining engineering structures (Soupios, et $a l, 2007)$.

Often, existing buildings are located over anomalous subsurface zones which are inappropriate for bearing the load of a structure. Recent damage, such as terrain subsidence and cracks in houses, call for attention and for further investigation using non-destructive geophysical methods to guide geotechnical investigations. Geotechnical and geophysical surveys are often the most cost-effective and rapid means of obtaining subsurface information, especially over large study area (Oyedele and Bankole, 2009, Sirles, 2006, Fatoba and Olorunfemi, 2004, Roberto et al, 2004 and Adepelumi and Olorunfemi, 2000). Subsurface soil characterization is a necessity for the citing of important civil engineering structures. In engineering geophysics, the question of the quality of building foundations is frequently

*Corresponding author’s e-mail address: kayode.oyedele@gmail.com addressed in the very late stages, when damage is either observed or expected (Olorunfemi, et al, 2004 and Parolai et al 2002, Delgado et al 2002).

In building construction, geophysics can be applied for investigation purposes to provide useful information regarding the early detection of potentially dangerous subsurface conditions (Oladele et al., 2015). The sources of hazards in civil engineering result essentially from undetected near-surface structures, such as cavities and/or inhomogeneities in the foundation geomaterials. Engineering properties of geomaterials are very important for civil engineers because almost everything they build is in, on or within the soils or rocks. Information related to the local soil conditions is vital for risk assessment and mitigation. Worthy of mention is that every geotechnical in-situ survey gives only discontinuous one-dimensional information for the subsurface conditions. In contrast, the application of engineering geophysics can provide either 2-Dimension or 3Dimension subsurface images of the study area.

In this study, geophysical and geotechnical methods were combined to ascertain the in-situ geo-mechanical properties of the subsurface. An integrated geophysical and geotechnical investigations offer very useful approach for characterizing near surface earth and thus can help in preparation before engineering structures are found on same. Geophysical methods are used to non-invasively and non-destructively detect and measure various physical properties of the earth. These physical properties, along with a good understanding of local geologic conditions, will reveal the geologic characteristics of the subsurface. For Engineering construction purpose, Electrical resistivity method is the most widely used because it is efficient, economical, has adequate resolution and capable of delineating subsurface geology effectively (Lunne et al. 1997, and Coerts, 1996). Among 
the different in-situ geotechnical tests, Cone Penetration Test (CPT) is considered the most frequently used method for characterization of geomedia. The CPT is a simple, quick, and economical test that provides reliable in situ continuous soundings of subsurface soil. Due to the soft nature of soil in the study area, the CPT is considered a perfect tool for site characterization. Geophysical tools do not replace geotechnical investigations, but supplement them by optimizing locations for geotechnical borings or filling information gaps between borings.

\section{LocAtion AND GeOlogicAl Setting OF THE STUDY AREA}

The investigated site shown in Figure 1 is located in the southwestern part of Lagos metropolis where the buildings are either sinking or severely damaged by crack systems Figure 2. This site was investigated to identify the reasons for the cracks and sinking. The information obtained can serve as a guide in the maintenance processes needed to increase the safety factor of the buildings. Moreover, delineating subsurface features responsible for these failures in the area can assist in the future planning for the construction of new buildings. The target is the general lithology and soil bearing capacity of the immediate subsurface, which will allow an interpretation of the competency of the subsurface structures and its ability to support the proposed underlying structure.

The objective of this work is to apply the relevant surface geophysical methods to investigate the subsurface setting of the area. This can lead to locating geological features that may cause cracking in buildings and increase the hazards in the study area. The combination of geophysical data and geotechnical measurements may greatly improve the quality of buildings.

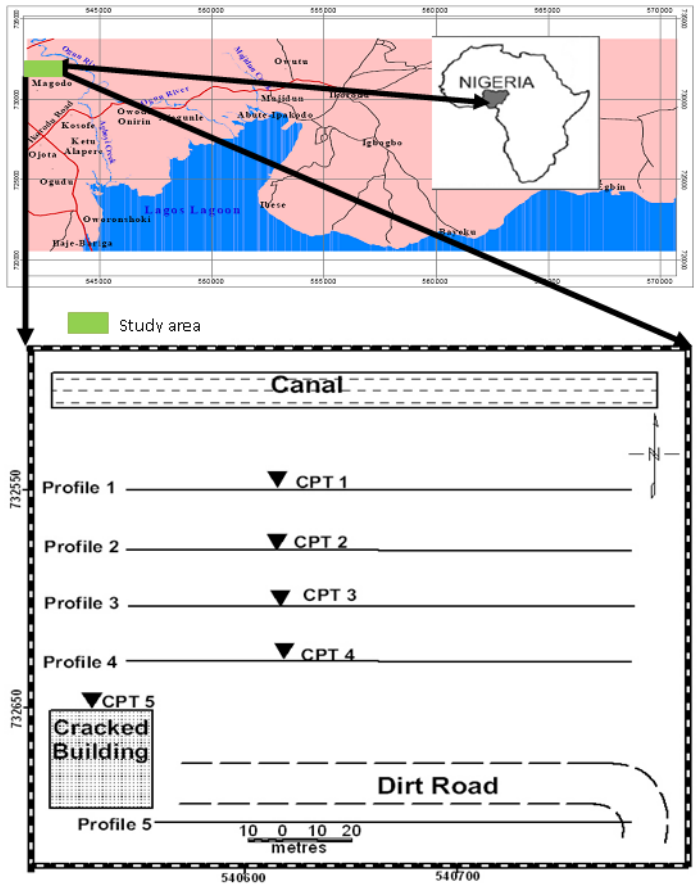

Figure 1: Location map of the investigated site showing the locations of the survey lines and CPT soundings.

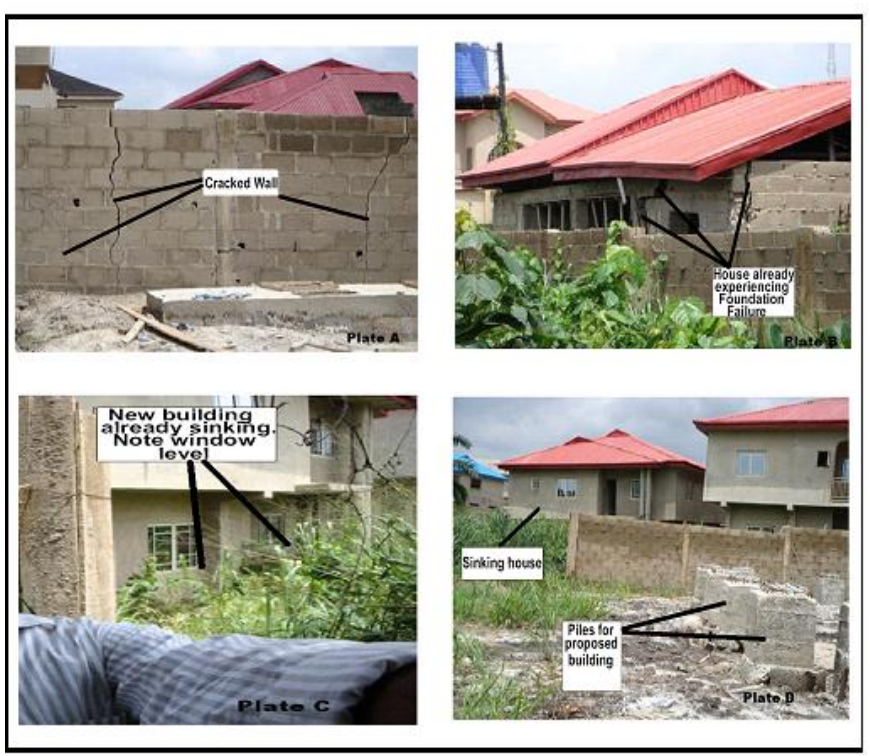

Figure 2: Photographs of cracks that appeared in wall and building at the site (top), and the sinking buildings near the site (bottom).

\section{Geological Setting}

The studied area Figure. 1 is located within the Nigerian sector of the Dahomey-basin, near the eastern margin of the Basin. Stratigraphy of the eastern Dahomey basin has been discussed by various workers and several classification schemes have been proposed. These notably include those of Jones and Hockey (1964); Omatsola and Adegoke (1981); Coker et al. (1983); Billman (1992), Elueze and Nton (2004).

The stratigraphy of Cretaceous to Tertiary sedimentary sequence of the eastern Dahomey basin can be divided into: Abeokuta Group, Imo Group, Ilaro Formation, Benin Formation, Coastal plain sands and recent alluvium. Lying unconformably on the Precambrian basement at the bottom of the sedimentary basin is the unfossilferous sandstones and gravels called the Abeokuta Group. On top of Abeokuta Group is the Imo Group which is essentially marine shale, sandstones, and limestones of Albian to Santonian ages. The Ilaro Formation, consisting dominantly of red loose sandy sediments overlies the Imo Group. The surface geology is made up of the Benin formation (Miocene to Recent) and the recent littoral alluvial deposits. The Benin formation, which consists of thick bodies of ferruginous and white sands, rest conformably on Ilaro Formation (Jones and Hockey, 1964). It is friable, poorly sorted with intercalation of shale, clay lenses and sandy clay with lignite.

\section{Methodology/Data AcQuisition}

\section{A. Geophysical Investigation}

The geophysical investigation employed Electrical Resistivity method via Constant Separation Traversing (CST) techniques with PASI terrameter. The Resistivity data were recorded with Wenner array along five profiles, $180 \mathrm{~m}$ long, at inter-electrode spacing ranging from $10 \mathrm{~m}$ to $60 \mathrm{~m}$. The Wenner array was chosen because, of all common arrays, it 
has the strongest signal strength which is an important factor in the study area with high background noise (Loke, 2000). In addition it is also relatively sensitive to vertical changes in subsurface resistivity below the centre of the array. Wenner is good in resolving vertical changes (i.e. horizontal structures). Before galvanizing the subsurface, lowest possible electrode contact resistance was assured. To enhance data quality, the measurements were stacked three times for each point along the profile. The resistivity data collected were processed by means of Dipro for windows (2001) modeling software in order to perform 2D geo-electrical data inversion.

The inversion routines are based on the smoothnessconstrained least squares method (Sasaki, 1992; Loke and Barker, 1996). This scheme needs no a priori information of the subsurface; the starting model was constructed directly from the field measurements. The quality of the inversion output was guided by acceptable minimum absolute root mean square error (rms error) between the measured and predicted apparent resistivity. Data were processed to produce colour cross-sections which indicate variation of earth resistivity values with depth.

However, geophysical inversion inherently surfers from non-uniquenes, which can be reduced by constraining the inversion by the use of additional information. Borehole data was used to constrain the resistivity interpretation for different lithological Formations. Lithologic log from borehole drilled by Tunlad Geotechnical Company $8 \mathrm{~m}$ southeast of this site was used for inferring the lithology and correlation.

\section{B. Geotechnical Investigations}

The geotechnical method on the other hand employed Cone Penetration Test (CPT). The CPT is an in-situ testing method used to determine the geotechnical engineering properties of soils and delineating soil stratigraphy (Robert, 1996). The test method consists of pushing an instrumented cone tip, 1.41inches at about $60^{\circ}$ into the ground at a controlled rate (usually $2 \mathrm{~cm} / \mathrm{sec}$ ). The tip resistance and sleeve friction due to its friction were measured. The resistance parameters were used to classify the soil strata and to estimate the strength and deformation characteristics of the soil in the type locality. CPT combines rapid and cheap insight into the mechanical properties of the subsurface in the upper tens of meters. The empirical relationship between cone resistance and formation resistivity has been established by Fadugba and Olorunfemi (2011).

Determination of Soil classification can be achieved by analyzing the CPT data (Coker, 2015). The qualitative and quantitative interpretation of the penetrometer test was shown to be capable of providing information about the structural disposition of the geomorphic shallow structures existing presand-fill (Adepelumi et al., 2009). In addition to stratigraphic and structural disposition, CPT interpretations by Adejumo (2012) produced reasonable evaluation of effective strength parameters for organic clay soils. Oyedele and Olorode (2010) determined shear strength, compressibility potential and bearing capacity of the subsurface layers using CPT with a view of identifying suitable lithology for building foundation (1984). Although CPT provides valuable information as to the strength of the soil, the information is restricted to the CPT location (Eslaamizaad and Robertson, (1998)). The locations of CPT tests and borehole drilled at study area are shown in Figure 1. CPTs were conducted at 75 $\mathrm{m}$ marked on four of the five profiles, to a maximum depth of $23 \mathrm{~m}$. The fifth CPT (CPT 5) was located in front of a cracked building and a VES coinciding with CPT locations was also conducted to enable stratigraphic correlation.

\section{INTERPRETATION}

\section{A. Geophysical}

Borehole log in Figure 3 shows the subsurface geology as that of a sequence of clay and sand of varying thickness. The result of 2-D resistivity image of traverse 1 is shown in figure 4a. The resistivity image shows a resistivity range of 20 - 300 Ohm-m. The section is characterized by a homogenous conductive zone $(<40 \mathrm{Ohm}-\mathrm{m})$ highlighted at the center of the section, surrounded by relatively high resistive zone. The highlighted body is located between $65 \mathrm{~m}$ $120 \mathrm{~m}$ from origin and has an approximate depth of $15 \mathrm{~m}$. This material was interpreted as clay while the resistive material was interpreted as sand.

The resistivity structure of traverse 2 in Figure $4 \mathrm{~b}$ also highlights the presence of the conductive body (clay) at around the depth of $15 \mathrm{~m}$, but shifted toward the origin of the traverse between $50 \mathrm{~m}-105 \mathrm{~m}$ from origin. The clay material is also surrounded by silty sand (< 165 Ohm-m). The similarity in geometry and depth of this material with clay occurrence in traverse 1 suggests the lateral continuity of the clay material.

The inverted model resistivity of traverse 3 in Figure $4 c$ shows more heterogeneity in its electrical response. It indicates the relatively conductive homogenous zone $(<40$ Ohm-m) located between 40 to $115 \mathrm{~m}$ at depth of about $15 \mathrm{~m}$. An approximately synclinal shaped medium sand $>200$ Ohm-m) occurred between 110 and $175 \mathrm{~m}$ from origin having thickness which varies to a maximum of $22 \mathrm{~m}$ at the center. This is underlain by silty sand ( $<165 \mathrm{Ohm}-\mathrm{m})$ at depth greater than $22 \mathrm{~m}$.

The resistivity section of traverse 4 (Figure $4 \mathrm{~d}$ ) is similar in all respect to traverse 3. This suggests that the geology remain the same beneath the two traverses. The major difference is in the size and configuration of the silty sand body, which occurs essentially as small resistive nuclei in resistivity section of traverse 4 . The resistivity structure of traverse 5 (Figure $4 \mathrm{e}$ ) reveals the presence of the recurrent homogeneous conductive zone at almost the same depth but which now extends beyond the origin of the traverse to $60 \mathrm{~m}$ mark from the beginning of the transect. From the $60 \mathrm{~m}$ mark, there occurs a large body of relatively resistive medium sand with incision of less resistive silty sand within which a pocket of sandy clay occurs at the surface. 


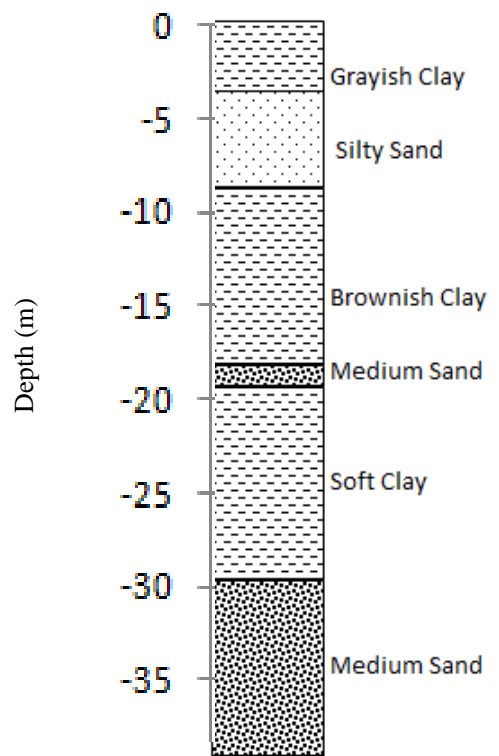

Figure 3: Borehole log showing the sequence of clay and sand in the study area

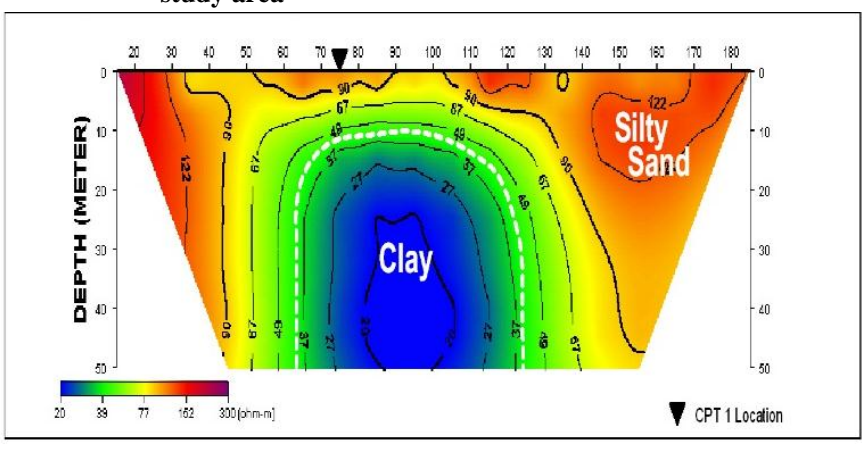

Figure 4a: Inverted resistivity sections along traverse 1

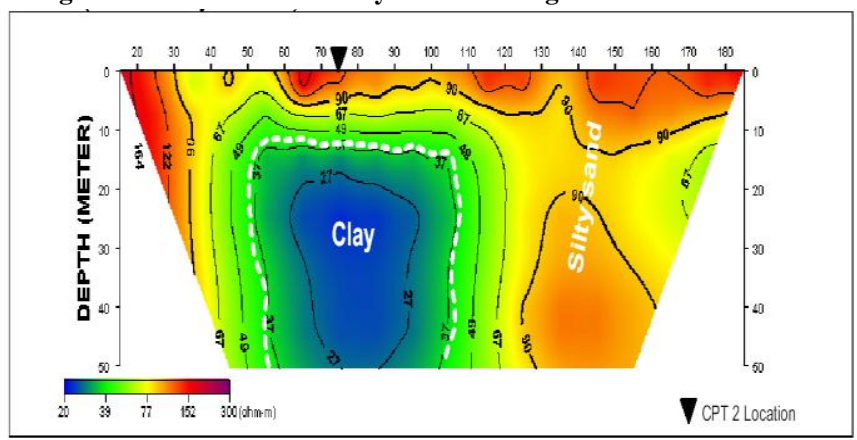

Figure 4b: Inverted resistivity sections along traverse 2

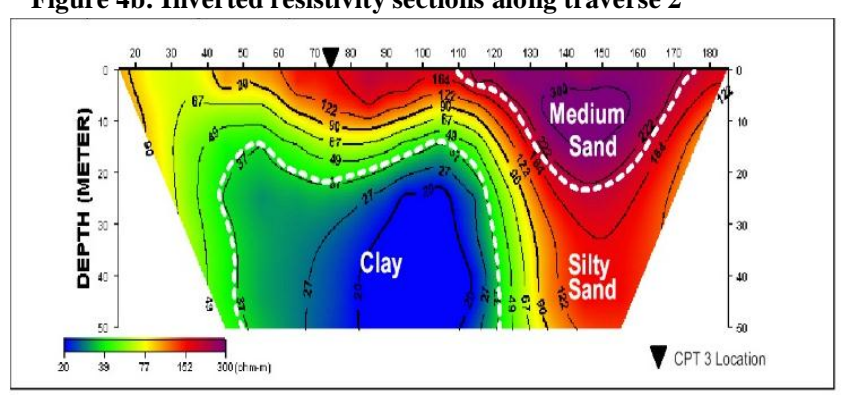

Figure 4c: Inverted resistivity sections along traverse

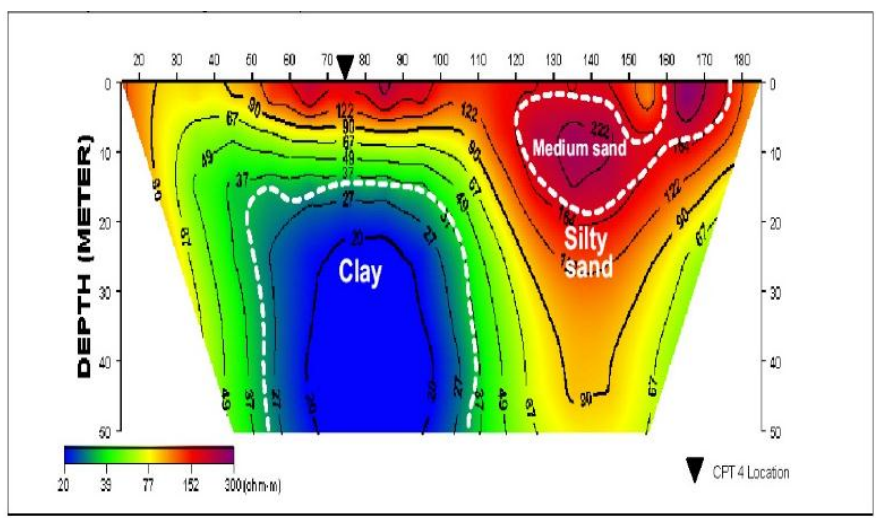

Figure 4d: Inverted resistivity sections along traverse 4

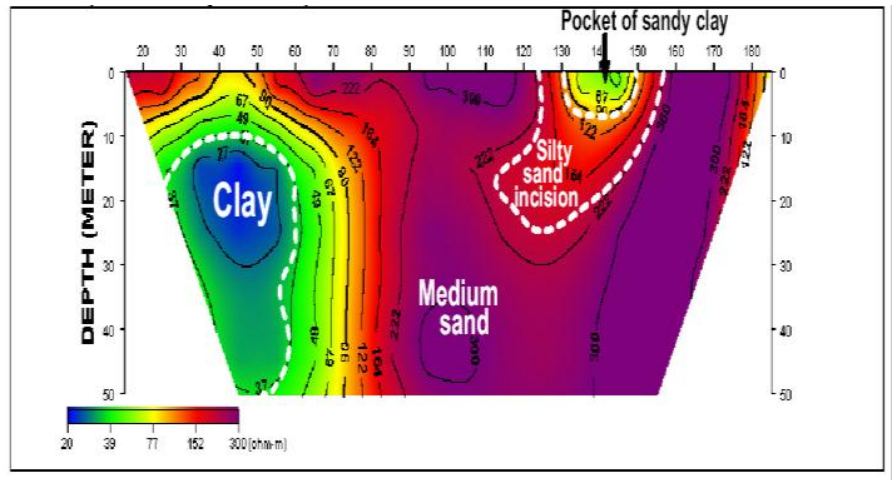

Figure 4e: Inverted resistivity sections along traverse 5.

\section{B. Geotechnical}

The CPT soundings curves obtained in the study area are shown in Figure 5. The curves obtained from CPT 1-4 have the same resemblance. The curves generally show relatively low resistance $\left(0-50 \mathrm{~kg} / \mathrm{cm}^{2}\right)$ for CPT 1 to CPT 4 over the entire penetration depth. This indicates the presence of materials of low penetrative resistance at these locations. This observation suggests that the sub-soils at these locations have poor geotechnical properties which can cause differential sinking of foundation soils with consequent damage to the buildings. This behavior was corroborated by the values obtained from interpreted geophysical data showing resistivity values of less than $40 \mathrm{Ohm}-\mathrm{m}$. CPT 5 on the other hand, presents a different scenario in that the penetration terminated in material of penetrative resistance of $120 \mathrm{~kg} / \mathrm{cm}^{2}$ at $19 \mathrm{~m}$ depth. This shows the occurrence of sand, a competent engineering material at $19 \mathrm{~m}$ depth, unlike in locations CPT 1 to 4 where no competent geo-material was found throughout the penetration depth. Although CPT provides valuable information as to the strength of the soil, the information is restricted to the CPT location (Eslaamizaad et al., 1998). 


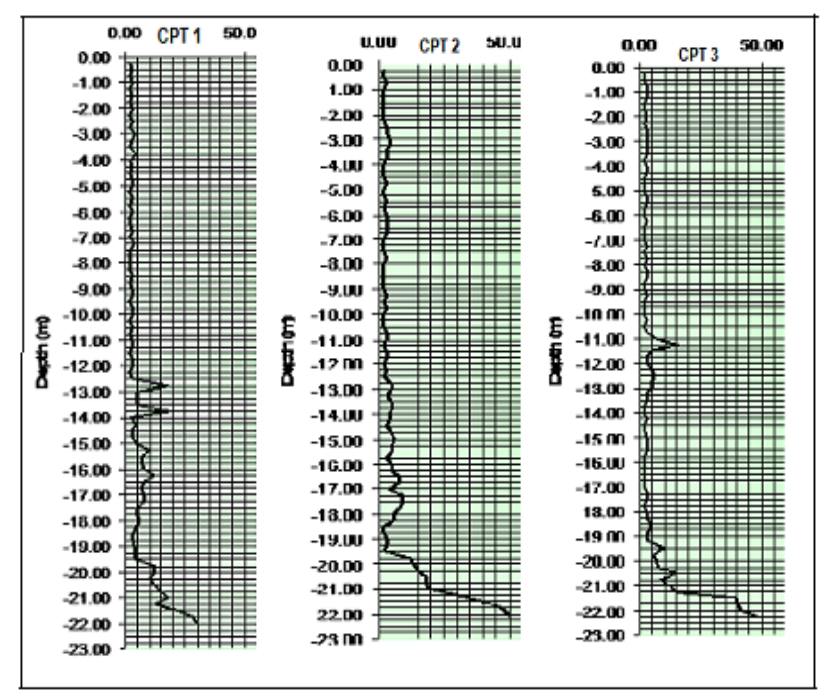

Figure 5a: CPT sounding curves for the study area in $\mathrm{kg} / \mathrm{cm}^{2}$.

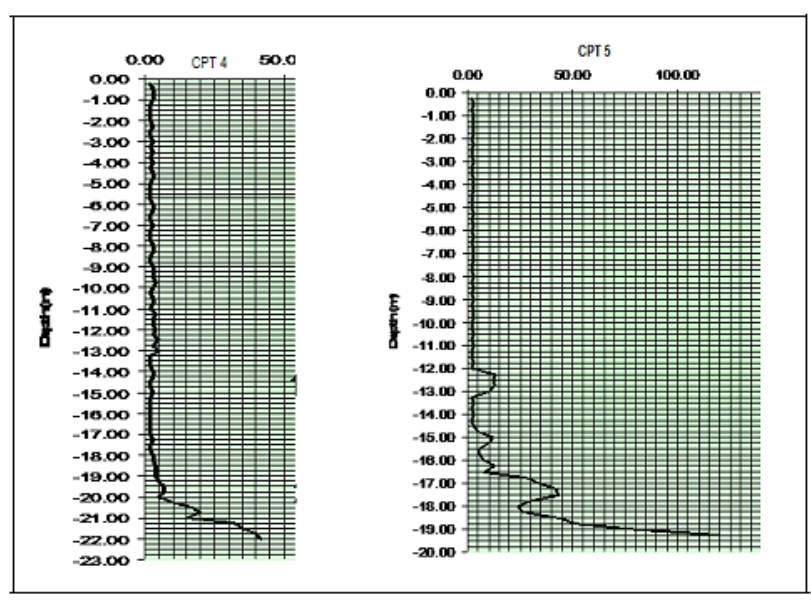

Figure 5b: CPT sounding curves for the study area in $\mathrm{kg} / \mathrm{cm}^{2}$ (contd.).

\section{INTEGRATION OF GEOPHYSICAL AND GEOTECHNICAL RESULTS}

Integration of CPT results with the resistivity section shows that CPT 1-4 terminated in low resistivity materials interpreted as clay. All the tomography images highlight a sub-surface heterogeneity in which pockets of clay are sandwiched within sandy materials. The presence of clay is viewed as being inimical to foundation health due to its low bearing capacity. In addition, some clay varieties expand when they absorb water. These clay types expand and contract through wet and dry periods. This is because water becomes bound to the clay particles and as such, structures sitting on top of such soils rise and fall with the soils. The result is differential foundation movement which causes cracking and distress in the foundation and finishes. This might probably responsible for structural failures in some of the structures erected in the study area in Figure 2.

The high compressibility characteristics of clay coupled with high shrinkage on drying, high porosity and low shear strength make it unsuitable for most construction work particularly when medium to massive structures are being considered. The clay soils, even when they are not under a long-term process of compression and stiffening, are more susceptible to subsidence (Soupios et al, 2007). However, citing building across such low bearing capacity material will results to foundation failure or differential settlement of the soils. Therefore, the presence of low penetrative resistance, low resistivity clay in the study area is identified as the cause of cracking and sinking of buildings in this area. On the basis of this, shallow foundation may not be possible in the study area unless adequate soil treatment is done; otherwise pilling to a competent depth of about $20 \mathrm{~m}$ is recommended. Piles can be seen already driven into the ground in the area. This would transfer loads of super structure to a stratum of high bearing capacity.

\section{CONCLUSION}

This study has presented an assessment of shallow subsurface involving the use of resistivity imaging and CPT to locate subsurface features responsible for building failures in the coastal area of Lagos. Interpretation revealed the presence of anomalous resistivity low interpreted as clayey materials. All the CPTs but one terminated in low penetrative resistance material which was also interpreted as clay. The geophysical and geotechnical signatures of the anomalous area suggested the presence of clay within a more competent sandy geomaterials. The presence of clay in the stratigraphic setup was viewed as the cause of structural instability of the building-soil system which resulted to differential sinking and subsequent cracking/failure of buildings.

This study has shown the usefulness of electrical resistivity imaging in determining the occurrence of clay in the subsurface strata prior to construction. The use of resistivity measurements is mainly applicable when large areas are to be investigated since these measurements provide continuous sections in contrary to geotechnical investigations which provide point information. Therefore, an integrated geophysical and geotechnical investigations offer very fast and relatively inexpensive approach for characterizing near surface earth in preparation for founding of engineering structures. It is therefore recommended that continuous foundation footings should not be placed on the identified clay soil. Foundations of large civil engineering structures around the study area should be safely anchored in form of piles on competent sand material.

\section{REFERENCES}

Adejumo, T. E., (2012). Shear Strength Parameters of Organic Clay Soils of Ikoyi, Lagos Nigeria. The Electronic Journal of Geotechnical Engineering, 17: 2135 - 2144

Adepelumi, A. A. Olorunfemi, M. O. Falebita, D. E and Bayowa, O. G., (2009). Structural mapping of coastal plain sands using engineering geophysical technique: Lagos Nigeria case study, Natural Science, 1: 2-9.

Adepelumi, A. A. and Olorunfemi, M. O. (2000). Engineering geological and geophysical Investigation of the reclaimed Lekki peninsula, Lagos, Southwestern, Nigeria. Bull. Eng. and Env, 58 (2): 125-131.

Coker, J. O., (2015). Integration of Geophysical and Geotechnical Methods to Site Characterization for Construction Work at the School of Management Area, Lagos 
State Polytechnic, Ikorodu, Lagos, Nigeria. International Journal of Energy Science and Engineering, 1 (2): 40 -48.

Coker, S. J., Ejedawe, J. E. and Oshiorienua (1983). Hydrocarbon source potentials of Cretaceous rocks of Okitipupa Uplift, Nigeria. Journal of Mining and Geology, 22: 163-169.

Delgado J, Alfaro P, Galindo-Zaldivar J, Jabaloy A, Lopez Garrido A C and Sanz De Galdeano C (2002). Structure of the Padul-Niguelas Basin (S Spain) from H/V ratios of ambient noise: application of the method to study peat and coarse sediments Pure Appl. Geophys. 159: 2733-49

Dipro for Windows. (2001). Dipro ${ }^{\mathrm{TM}}$ Version 4.0 Processing and Interpretation Software for Dipole- Dipole Electrical Resistivity Data. KIGAM, Daejon, South Korea.

Elueze, A. A. and Nton, M. E., (2004). Organic geochemical appraisal of limestones and shales in part of eastern Dahomey basin, southwestern Nigeria. Journal of Mining and Geology, 40 (1): 29-40.

Eslaamizaad S. and Robertson P. K. (1998). Cone penetration resistance of sand from seismic tests, in Robertson PK, Mayne PW, Eds., Geotechnical site characterization: Balkema, 1027-1032.

Fadugba, O. I. and Olorunfemi, M. O. (2011). Development of Empirical Equations relating Formation resistivity and Cone Tip Resistance using Sedimentary and Basement Terrains of Nigeria as case study. The Pacific Journal of Science and Technology, 12 (2): 548-557.

Fatoba, J. O. and Olorunfemi, M. O. (2004). Subsurface sequence delineation and saline Water Mapping of Lagos State, Southwestern, Nigeria. Global journal of geological sciences, 111-123.

Jones, H. A. and Hockey, R. D. (1964). The geology of part of Southwestern Nigeria. Geological Survey of Nigeria. Bull. 31,87P.

Loke, M. H. (2000). Electrical Imaging Surveys for Environmental and Engineering Studies: A Practical Guide to 2D \& 3D Surveys. Available at www.terrajp.co.Jp/lokenote.pdf,2004. P.59.

Loke, M. H. and R. D. Barker, (1996): Practical techniques for 3D resistivity surveys and data inversion. Geophysical Prospecting, 44: 499-523.

Oladele, S., Oyedele, K. F. and Dinyo, M. O., (2015). Pre-construction geoelectrical and geotechnical assessment of an engineering site at Alapere/Agboyi, Lagos, Nigeria, Ife Journal of Science, 17 (3): 543 - 552.

Olorunfemi, M. O., Idornigie, A. T., Coker, A. T., and Babadiya, G. E. (2004). On the application of the electrical resistivity method in foundation failure investigation - A case study. Global journal of geological sciences, 2 (1): 139-151.

Omatsola, M. E. and Adegoke, O. S. (1981). Tectonic evolution and Cretaceous Stratigraphy of the Dahomey basin. Journal of Mining Geology, 18 (1), P.130 -137.

Oyedele, K. F. and Bankole, O. O. (2009). Subsuface stratigraphic mapping using geophysics and its impact on urbanization development in Arepo area, Ogun State, Nigeria. New York Science Journal, 2 (2): 31 - 45.

Oyedele, K. F. and Olorode, D.O., (2010). Site Investigations of Subsurface Conditions Using Electrical Resistivity Method and Cone Penetration Test at Medina Estate, Gbagada, Lagos, Nigeria, World Applied Sciences Journal 11 (9): 1097-1104.

Parolai S, Borman $P$ and Milkreit C (2002). New relationships between $\mathrm{Vs}$, thickness of sediments and resonance frequency calculated by $\mathrm{H} / \mathrm{V}$ ratio of seismic noise for the Cologne area (Germany) Bull. Seismol. Soc. Am. 92: 2521-7.

Robert M. (1996). Avoiding Foundation Failures. Second edition, John Willey publisher: 5-20.

Roberto, B., Enrico, G., Federica, A., and Giorgio, G (2004). Geophysical approach to the environmental study of a coastal plain. Geophysics, 68 (5): 1446-1458.

Sasaki, Y. (1992). Resolution of resistivity tomography inferred from numerical simulation. Geophys. Prospect, 40: 453-464.

Sirles, P., (2006). Advancements in 3D Subsurface Modeling using Seismic Refraction Data- A New Perspective, in Proceedings for GEOPHYSICS 2006, the 3rd International Conference on Applied Geophysics, St. Louis, MO, December 2006.

Soupios P., Georgakopoulos P., Papadopoulos N., Saltas V., Vallianatos F., Sarris A. and Makris J. (2007). Use of engineering geophysics to investigate a site for a building foundation. J. Geophys. Eng, 4 (1): 94-103. 